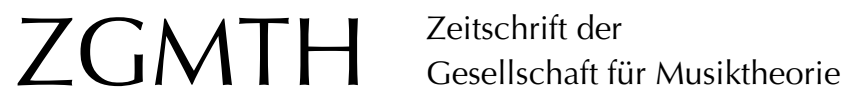

Krims, Adam (2010): Music Theory, Historically-Informed Performance, and The Significance of Cities. ZGMTH 7/Sonderausgabe [Special Issue], 241-259.

https://doi.org/10.31751/571

(C) 2010 Adam Krims

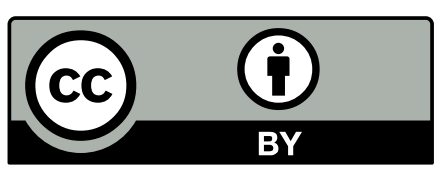

Dieser Text erscheint im Open Access und ist lizenziert unter einer Creative Commons Namensnennung 4.0 International Lizenz.

This is an open access article licensed under a

Creative Commons Attribution 4.0 International License.

veröffentlicht / first published: 01/11/2010

zuletzt geändert / last updated: 15/10/2010 


\title{
Music Theory, Historically-Informed Performance, and The Significance of Cities
}

\author{
Adam Krims
}

This article examines three recordings from the early heyday of HIP, made around the same time, all of Beethoven's First Symphony, Op. 21, focusing on its last movement. It isolates the feature of wind/string balance, widely touted at the time as an advantage of the HIP approach, and measures them at key points of the movement; the resulting similarities of two of the recordings, both from London-based performers, and their pronounced divergence from the third, featuring East-Coast American performers, suggests the possibility that music workers (performers, but also engineers, producers, etc.) informed each others' aesthetic preference and priorities, whether implicitly or explicitly. Recent theories from urban geography are raised in order to explain the kind of location-based learning that may account for such similarities and divergences, showing that ideas nurtured in discussions of urban creativity can contribute quite substantially to the concerns of music theory.

Dieser Artikel untersucht drei Aufnahmen des IV. Satzes aus Beethovens 1. Sinfonie, op. 21. Die Aufnahmen stammen alle aus der frühen Blütezeit der Historischen Aufführungspraxis. Untersucht und gemessen wird die Balance von Holzbläsern und Streichern, die immer als ein Vorteil des Ansatzes der Historischen Aufführungspraxis gesehen wurde. Die Aufnahmen, die von Londoner Interpreten stammen, ähneln einander und unterscheiden sich deutlich von der dritten Aufnahme, von Musikern von der amerikanischen Ostküste. Diese Ergebnisse lassen vermuten, dass die an der Aufnahme beteiligten Personen (Musiker, aber auch Tonmeister und Produzenten etc.) sich implizit oder explizit hinsichtlich ihrer ästhetischen Präferenzen und Prioritäten beeinflussen. Aktuelle Theorien aus dem Bereich der surban geography` werden für die Erläuterung solcher Ähnlichkeiten und Unterschiede herangezogen. Dies zeigt, dass Ideen, die im Kontext urbaner Kreativität diskutiert werden, sich mit musiktheoretischen Fragen substanziell berühren können.

A substantial and impressive music-theoretical literature has now been developed, centering on musical performance. ${ }^{1}$ While the scholars that have addressed musical performance have been a mixture of musicologists and music theorists, and their work has appeared in both musicological and music-theoretical venues, musical performance is most decidedly a concern for theorists. For most of the history of music theory, especially its disciplinary existence in North America, performance has been relegated to the very margins of the literature and more commonly observed in ethnomusicology, where

1 For example Dineen 2009, McClary 2009, Honisch 2009, and Cook 2005. 
integrating questions of performance has always occupied a pride of place. ${ }^{2}$ For music theorists, on the other hand, the musical work has always been central, and the workconcep $^{3}$ has long served to displace questions of how that work may be projected in real time; indeed, even many of the studies that do address musical performance do so by using the musical score (so: the work) as a prescriptive premise, taking the 'work itself' as having a nature that, properly analyzed, may dictate its best possible realization. ${ }^{4}$ Such studies can certainly be of value, suggesting, at a minimum, that an interested performer may generate articulational, phrasing, dynamic, and other ideas from structures deemed to characterize a given piece. Other theoretical/analytical approaches to music performance deal largely with the recorded literature and offer often suggestive and enlightening pictures of changing performance traditions and trends; ${ }^{5}$ largely empirical in nature, such studies nevertheless offer crucial links to concepts of changing aesthetic trends and notions of different repertories' aims and realization. In such studies, which necessarily deal mainly with the twentieth century, one may see a fascinating supplement to histories of twentieth-century music, a history previously focussed on compositional avant-gardes.

While both these theoretical traditions of examining musical performance have plenty to offer the interested music theorist and have generated some exceptionally fine work, very few of them tend to tie in the aesthetic results (or in the case of the first tradition, prescriptions) with larger historical forces. In fact, most of those concerning themselves with such larger social conjunctions have been musicologists, ${ }^{6}$ themselves more interested in questions of overall style and broad articulation than in the questions of musical organization that tend to preoccupy music theorists. This essay will attempt to argue that close attention to performance, albeit on select moments and in selected parameters, can disclose aspects not only of individual performances, but also of geographically-determined performances, and perhaps of urban life, as well. Such a sweepingly ambitious argument cannot be demonstrated to the level of apodictic certainty in any context, much less the length of this essay; but I do hope to show that such connections can be helpful, and that musical detail can be talked about as having some geographic determinations, and not simply in terms of regionality. And most important, as such matters deal with how music actually sounds, and the relationship between the score and its realization as actual music in real time, it is very much the concern of music theorists.

Classical-music players, critics, and scholars have been known, on occasion, to deploy notions of regionality in their discussions of musical performance style (such as the notion of a Russian school of piano playing presumably traceable to Chopin and Liszt (!) or that of a Hungarian violin school dating to early-nineteenth-century Vienna). And especially among professional performers, pedigree is often flaunted in terms of a lineage from individual pedagogues, all the better if the originating pedagogue is a wellknown composer or, at a minimum, a legendary teacher. One of the arguments that will

2 MacDonald 2009, Palourde 2008.

3 Damschroder 2008, Cook 2007.

4 Dodson 2008.

5 Day 2000, Leech-Wilkinson 2009.

6 For example, Taruskin 1995, Butt 2002, Fink 2005. 
be advanced in this essay is that performance traditions may, on the contrary, be urban phenomena, and that rather than speak of either nations or individuals, those wanting to trace geographies of performance might do better to speak of an urban style of performance. I will shore up this argument using theories from the discipline of urban geography, before turning to some ethnographic work on HIP performance and pedagogy, as well as some music-theoretical analyses of some geographically-related recordings.

It is perhaps not revelatory to observe that the best-known and most influential conservatories tend to be located in major cities. While cultural and educational institutions in general will be found at crossroads of human travel and commerce - and there are, of course, some exceptions - the importance of the location of conservatories in major cities surpasses the sheer fact of their being conveniently located; the urban setting of conservatory also has some sknock off effects that have been studied by urban economic geographers like Michael Storper, ${ }^{7}$ Alan Scott, ${ }^{8}$ and others who have studied the urban settings of creativity. Some of those effects, visible in descriptions like that of Kailan Rubinoff ${ }^{9}$ of the Conservatorium van Amsterdam, are the presence of a large pool of relevant specialized labor, as well as a network of workers with complementary specialized skills (such as music critics, journalists, promoters, and so on). Storper and Scott, in particular, however, also underline how certain kinds of learning in creative economies (like that of the conservatory) only seem to take place by face-to-face contact. ${ }^{10}$ Storper and Venables underline "the advantages of F2F as a communication technology, particularly when much of the information to be transmitted cannot be codified."11 This applies, of course, to environments such as the formal learning environment of the instrumental or vocal lesson (in which personal attendance and participation are crucial), but it also applies to the many less formal environments which cities provide for reinforcement and development of cultural taste and preference, such as the concert halls, restaurants, cafés, coffee houses, and other locales in which socialization and professional development mix. Rubinoff describes such outings among students in Amsterdam, ${ }^{12}$ and Scott ${ }^{13}$ describes them more formally as "the social construction of localized politico-cultural assets such as mutual trust, tacit understandings, learning effects, specialized vocabularies," and other forms of cultural learning and relationship-building that depend on F2F interactions in the facilities that cities alone offer. Rubinoff mentions the advantages of the proximity of universities in Amsterdam; ${ }^{14}$ not only the city's affording the presence of such institutions, but also the kinds of informal environment in which its culturally saturated learning can be shared - both of these are key assets that Amsterdam affords conservatory students for learning the information-heavy performance skills that will be

7 For example, Storper and Venable 2004.

8 Scott 2000.

9 Rubinoff 2006.

10 Abbreviated as F2F. Storper and Venables 2004, 361.

11 Storper and Venables 2004, 352.

12 Rubinoff 2006, 142-143.

13 Scott 2000, 19.

14 Rubinoff 2006, 21, 133, 140. 
crucial to their future. ${ }^{15}$ Of course, urban geographers have long thought of leisure facilities such as bars, cafés, restaurants, and other spaces of socialization as urban assets; but Storper's and Scott's findings suggest that they may be more crucial to the success of institutions such as the Conservatorium than one might otherwise assume. And, of course, things like the minute variations in rhythm, phrasing, breathing, and touch that distinguish performance style - these are precisely the kinds of cultural information whose transmission (as Storper and Venables require) cannot be codified; this is why they are almost always transmitted by a played or sung example. Cities provide those spaces in which they and broader musical preferences are conveyed, as well as other culturallysaturated values like stylistic preference and musical taste.

The kinds of cultural transmission and taste-formation described by Storper, Scott, Venables, Rubinoff, and others ${ }^{16}$ suggest that, rather than speaking of performance styles in national terms, as is commonly done, one might re-conceive performance styles as matters of urban concentration (and, indeed, Rubinoff speaks of rivalries and perceived stylistic differences between students and faculty at the Conservatorium van Amsterdam and those at the Royal Conservatory in the Hague). Of course, performers themselves tend to speak of performance skills (and, usually only by implication, cultural transmission and taste-formation) in terms of 'heritage,' most often featuring in their biographies the names of their teachers; and quite evidently, one should not exclude such individual connections from consideration. But the most common geographic conceptions of performance style tend to construct a national scale; most of the balance of this essay will investigate that conception, looking at multiple recorded performances of music with the idea of finding commonalities that can be attributed to a particular urban transmission of stylistic preferences. Of course, such an attribution may preclude other possible influences on performance style which may not in themselves be urban in scale or origin; but finding performative resemblances among different recordings of artists trained in the same urban center could, at a minimum, suggest that urban cultural cultivation may shape the sound of a performed piece in ways that score-based approaches cannot illuminate.

Of course, measuring such things requires tools that do not rely on standard musical notation, but rather measure execution of the written score, timing events and measuring various aspects of the musical signal emitted by the performance. As one might imagine, the most reliable, and certainly the only repeatable, conveyance of a musical performance which the music theorist could measure is the recording, which is why the majority of the studies of musical performance have focused on recordings. ${ }^{17}$ Of course, any music-theoretical study of recordings stands to learn something about its limits from the studies of music-recording culture, and in particular, the ways in which the situation of recording has affected the performance itself; ${ }^{18}$ in a sense, in studying a musical recording (in particular, a commercially-produced recording such as those to be discussed

15 Rubinoff does not herself focus on the significance of the urban setting.

16 Such as Shelemay 2001.

17 For example, Bowen 1999, Cook 2003, Leech-Wilkinson 2009.

18 For example, Katz 2004, Sterne 2003. 
here), a music theorist is studying a particular kind of musical performance, which can only with some serious caveats be deemed to address the situation of musical performance in toto. Nevertheless, because of their availability for study and repeatability for the purpose of measurement - and, one might be tempted to add, because recordings represent the occasions for many, if not most, people's engagement with music - recordings will constitute the objects of study for the remainder of this essay.

In particular, it will be useful and informative to examine performances of the same piece by performers who could reasonably be said to have adapted some of their manners of execution in the same urban environment, around the same time; similarities (and differences) can then be noted in their performance style, suggesting at least the possibility that the urban formation of musical taste may lie behind them. In order to increase the likelihood of the latter, it will also be helpful to compare the two recorded performances to a third recorded performance of the same piece, that third recording being of a performer who cultivated her/his style in a different urban environment. Such a comparison with a 'control' recording will limit the chance that resemblances between the two initial recordings result from broader-based performance traditions, circulation of recordings and broadcasts, and other factors that are not directly related to urban transmission of musical taste and practices. While the pool of examples that can be addressed in an essay of this length is certainly small (here limited to three recordings), the results can at least be suggestive of a much larger picture.

For these purposes, I have chosen to compare two recordings of the final movement (Adagio/Allegro molto e vivace) from Beethoven's first symphony, Op. 21, made by Christopher Hogwood (with the Academy of Ancient Music) and Roger Norrington (with the London Classical Players); Hogwood's recording was made in November 1983 in London, while Norrington's was made in London in September 1987. Both conductors, at that time, were principally associated with London's then so-called 'early music' performance movement, though both had also partaken of the international appearances and training typical of conductors (Hogwood having studied harpsichord with Gustav Leonhardt in Amsterdam, for example). Hogwood founded the Academy of Ancient Music in London in 1973, while Norrington founded the London Classical Players there in 1978 (having previously founded the Schütz Choir in London in 1962). The urban milieu which is being invoked here, then, is precisely that, as an agglomeration of performance and rehearsal venues, recording companies (such as Decca, which recorded Hogwood under the imprint L'oiseau Lyre, and EMI, which recorded Norrington), and, of course, spaces of association, socialization, and the sharing of aesthetic values and knowledge. We will return to this concept at the end of this essay; but for now, the best information will come from examining the recordings.

Those recordings thus both were produced in the very earliest part of the period of HIP recording of Beethoven's symphony, and, in fact, Hogwood's was the first commercially-released recording of a Beethoven symphony on what were then called 'original instruments' and Norrington's the second..$^{19}$ The liner notes for each issue, and the media reception of the recordings, both tend to stress the differences of the performances from 
those then prevalent in timbre, orchestral balance, and rhythm: Clive Brown, in the notes accompanying Hogwood's recording, stresses the "brighter, cleaner sound, sharper contrasts, and uncomplicated, rhythmical performances." ${ }^{20}$ How, exactly, a performance could fail to be "rhythmical" may strike a reader as a salient question; in context, Brown seems to be referring to a constancy of rhythm, as against the localized inflections imposed by conductors in the performance tradition since Beethoven's time. ${ }^{21}$ Likewise, the notes for Norrington's recording, written by Norrington himself, emphasize the differing timbres of the instruments, ${ }^{22}$ but above all the difference in note lengths and tempo; ${ }^{23}$ indeed, the score's tempo markings are marked (quite unusually) for each movement on the reverse of the compact disc, and the media reception of the recording underlined Norrington's maintenance of those tempi. ${ }^{24}$

Somewhat lost in the public discussions of Norrington's following of the metronome markings, however, were the fundamental resemblance of his recorded tempi to those of Hogwood. In this first symphony, Op. 21, for instance, Norrington's movement timings, as stated on the CD, are $8^{\prime} 49^{\prime \prime}, 7^{\prime} 08^{\prime \prime}, 4^{\prime} 19^{\prime \prime}$, and $5^{\prime} 30^{\prime \prime}$, respectively, for the first, second, third and fourth movements, while Hogwood's, for the same movements, are given as $8^{\prime} 45^{\prime \prime}, 7^{\prime} 15^{\prime \prime}, 4^{\prime} 12^{\prime \prime}$, and $5^{\prime} 32^{\prime \prime}$. Turning now specifically to the symphony's final movement, one can also see similarities in more localized detail; Example 1 shows how, displaying the waveform of Hogwood's performance of the entire movement on top, with that of Norrington just below it.

The timings of the respective performances are marked above the two waveforms. One can observe, there, a striking match. Of course, the rather inflexible approach to tempo (critiqued by many reviewers, then and since) may seem to account for these similarities; but given that this movement features both an Adagio introduction and an Allegro molto e vivace body, the two performance's coincidence remains striking. But tempo is, of course, while the most easily measured, still only one of many aspects of music performance, and a closer look at musical detail could offer a more nuanced and wide-ranging idea of their performance style.

Example 2 isolates a section of that final movement from both performances, corresponding, in the score, to measures 164 through the end of the movement. (Thematically, the beginning of this excerpt corresponds to the reprise of the opening theme of the Allegro molto e vivace in the B section of the movement's binary form.)

While here, as in Example 1, the similarities in both the timing and the relative scale of events (the latter reflected in the overall shapes of the waveforms) may be striking, that again could easily reflect the combination of the reading of the same score, as well as a

20 Hogwood 1986, 7.

21 These are also the liner notes that, famously, offer the metaphor of cleaning dirt off an old painting, which provokes the later, angry response of Richard Taruskin $(1995,150)$.

22 Norrington 1988, 4.

23 Norrington 1988, 5.

24 For example, Johnson 1990, 57. 


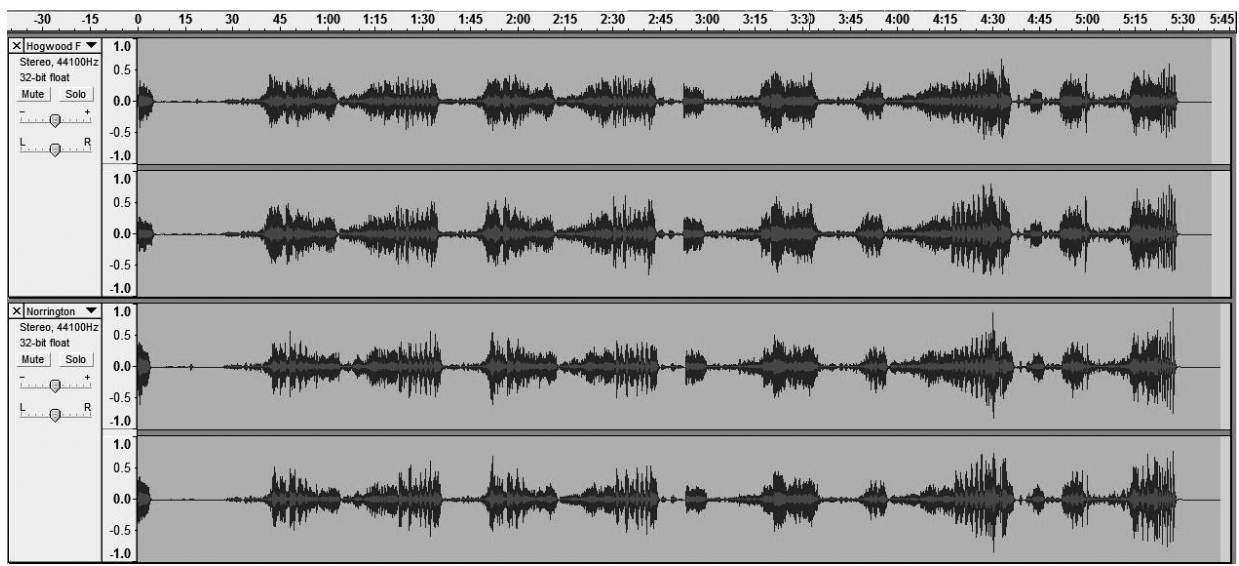

Example 1. Christopher Hogwood's and Roger Norrington's recordings of the last movement of Beethoven, Op. 21, as represented by Sonic Visualiser ${ }^{25}$

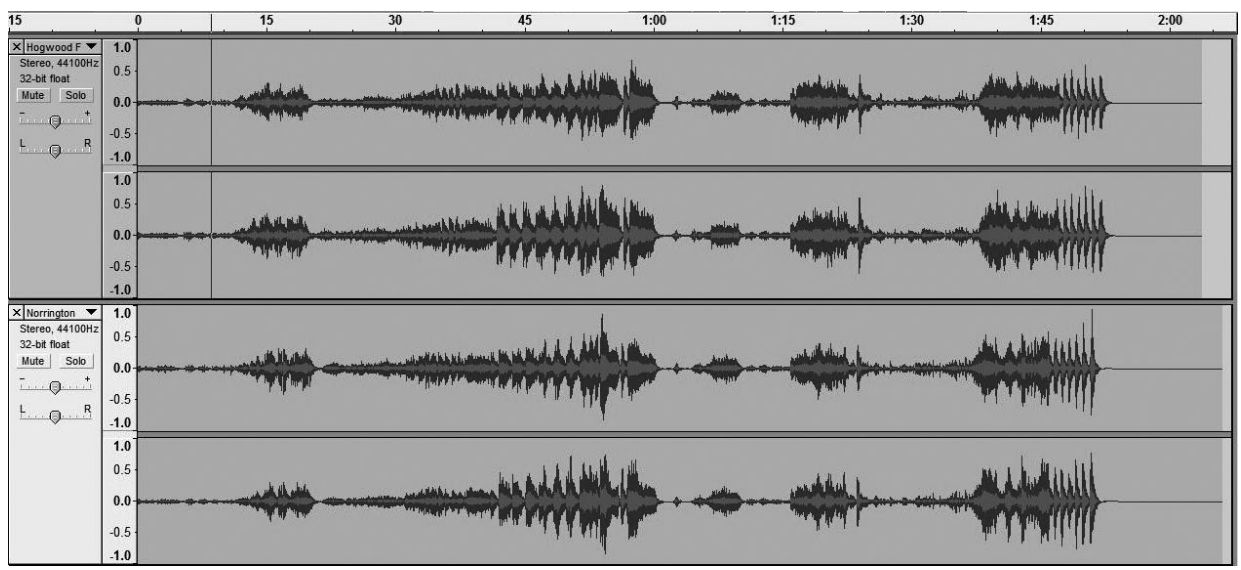

Example 2. Measures 164 to the end of Christopher Hogwood's and Roger Norrington's recordings of the last movement of Beethoven, Op. 21, as represented by Sonic Visualiser ${ }^{25}$

similar tempo. ${ }^{26}$ In particular, it would make sense now to look at another feature more characteristic of the public life of HIP performance, namely orchestral balance, and in particular, the balance between the strings and other orchestral choirs. Even well before

25 Sonic Visualiser is a free software for music analysis developed at the Centre for Digital Music at Queen Mary, University of London. It can be downloaded from www.sonicvisualiser.org (last accessed 8 February, 2010). See explanation below.

26 It is interesting to note, however, that when the Norrington recording was released, much media discussion focused on his adoption of Beethoven's metronome markings as rendering it strikingly different from previous recordings, whereas, as has been shown here, his tempos were virtually identical to those of Hogwood, released the year before. 
the issue of these two recordings, that issue of balance was basic to some of the publiclystated goals of the HIP movement; Nikolaus Harnoncourt stated it this way in a 1985 interview: "The old instruments were [at the time of the founding of Concentus musicus Wien in 1957] an immediate solution to problems of balance, texture, articulation." ${ }^{27}$ Harnoncourt's statement dovetails with the oft-presented argument, from HIP practitioners and proponents, that the orchestras of Beethoven's time (or that of any eighteenth- or early-nineteenth-century composer) usually featured fewer massed strings than that of the (then) modern orchestra, and that, further, the timbres of both the strings and the other instruments were different such that the balance of orchestral voices in modernorchestra performances now differs substantially from that envisioned by the composers. ${ }^{28}$ Clive Brown, in his notes for Hogwood's recording, is perfectly direct on this point: "[T] he balance of the orchestra [in Beethoven's time] was weighted much more heavily in favour of the wind instruments." ${ }^{\prime 29}$

Given this fairly concrete aesthetic goal, one might well examine this passage for evidence of to just what extent our recordings reflect or convey the goal of enhancing the balance of the non-string choirs against the strings. While assessing that balance is normally a matter of sensory perception, and thus subject to any manner of complex and highly individualized impressions, one may also measure such a balance more objectively, through plotting the recording and performing a peak frequency spectrogram. ${ }^{30}$ Such an interpretive representation of the two scores enjoys the advantage of offering a measure of the recordings that can be verified, independent of subjective impressions. On the other hand, of course, the sidelining of subjectivity does sideline the re-insertion of our observations of our musical experience; but since the goal here is to measure similarity rather than to assess musical experience, this kind of objectivity will serve as an advantage.

For the sake of assessing the similarities and differences in instrumental balance in the two recordings, we will isolate two particularly revealing moments in each one, corresponding to measures 179-181 and 200-203. The reason for choosing these two passages is that they offer particularly advantageous opportunities to measure orchestral balance. To understand why these two passages are particularly relevant, one must consider what a peak-frequency spectrogram measures. The $X$ axis is quite simply the time of the recording. The $Y$ axis displays frequencies, in the case of the peak-frequency spectrogram corresponding to those frequencies normally heard in music; it is graded logarithmically, in order to correspond to heard pitch (since pitch perception varies logarithmically with frequency). In addition, this particular peak frequency spectrogram, found

27 Kehoe 1985, 1045.

28 Norrington himself was often more sophisticated and nuanced in his claims, saying in the same liner notes to this recording that "Orchestra size was not [in Beethoven's time] a crucial factor. Orchestras played equally in very small and very large formations ..." (Norrington 1988).

29 Hogwood 1986, 6.

30 A peak frequency spectrogram enjoys two features which make it especially appropriate for this discussion. First, it confines its display areas to the audible range in which musical sound is usually generated. And second, it displays only those bins that are stronger than their neighboring frequency bins, thus making it easier to discern individual notes. 
in the software Sonic Visualiser, also displays the intensity of the signal corresponding to any given frequency and time; that intensity is represented visually by color and also numerically in the software's display, when one runs the cursor over the corresponding location on the display. The display offers information about the entire recording (both channels of the stereo recording simultaneously), rather than identifying any particular sound source within the recording space; thus, in order to assess the contribution of any particular instruments, one need find passages in which some frequencies may be identified uniquely with one instrument in the score - not an easy task, since doubling is so common in orchestral composition in this period. The two passages chosen, then, feature just that, i.e., moments in which certain frequencies can be uniquely identified with wind instruments and other uniquely with strings, in particular violins. ${ }^{31}$ In measures 179-181, the $G^{4}$ and $E^{4}$ of the first and second bassoons, respectively, can be isolated, along with the $A^{5}$-to- $F^{6}$ and $A^{4}$-to- $F^{5}$ scalar melodies of the first and second violins, respectively; Example 3 marks the relevant pitches in the score.

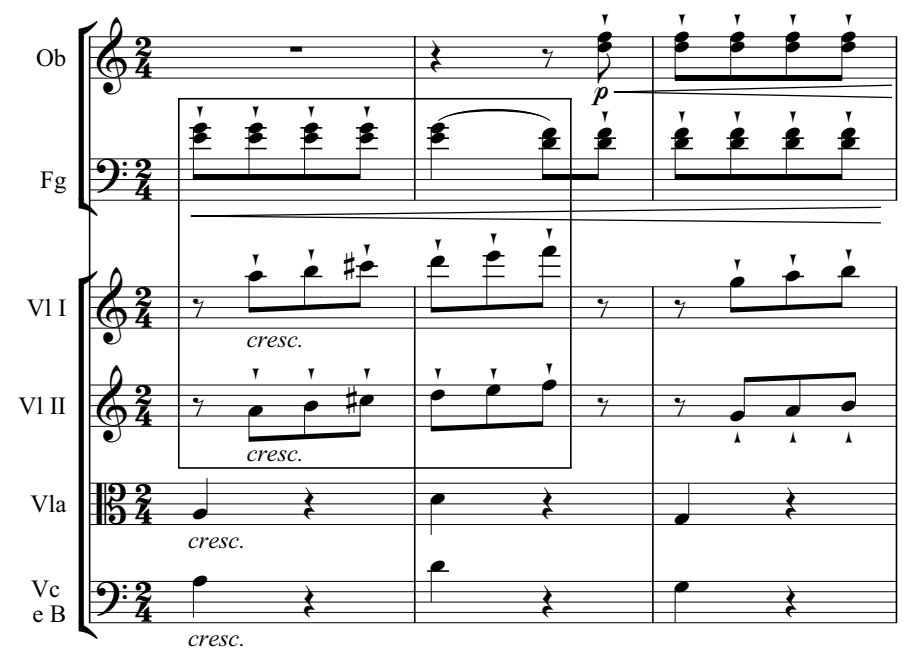

Example 3.

Beethoven, Symphony No. 1, Last Movement, mm. 179-181

In measures 200-203, one may isolate the $E^{5}-F^{5}$ of the oboe (not the final $G^{5}$, since it is doubled by the first clarinet and first horn, and excluding the downbeat of measure 200, because of the doubling of the first violins), along with the melodic figure of $C^{5}-C^{6}-C^{6}-B^{5}-D^{6}$ in the first violins, and the same figure, an octave lower, in the second violins; Example 4 marks the relevant pitches in the score. The two selected passages also have the advantage of representing both a moment of wind soloing (measures 179181) and a more ripieno texture (measures 200-203), thus arguably giving an account that can better be generalized.

31 Or rather, almost uniquely, since, of course, every musical note produces an entire spectrum of frequencies, there may also be some contribution from other parts whose fundamental pitches are lower. Most likely, this contribution will not be sizeable, however, and one can easily observe, in the spectrogram, the correspondence of major signals to events in the score. 


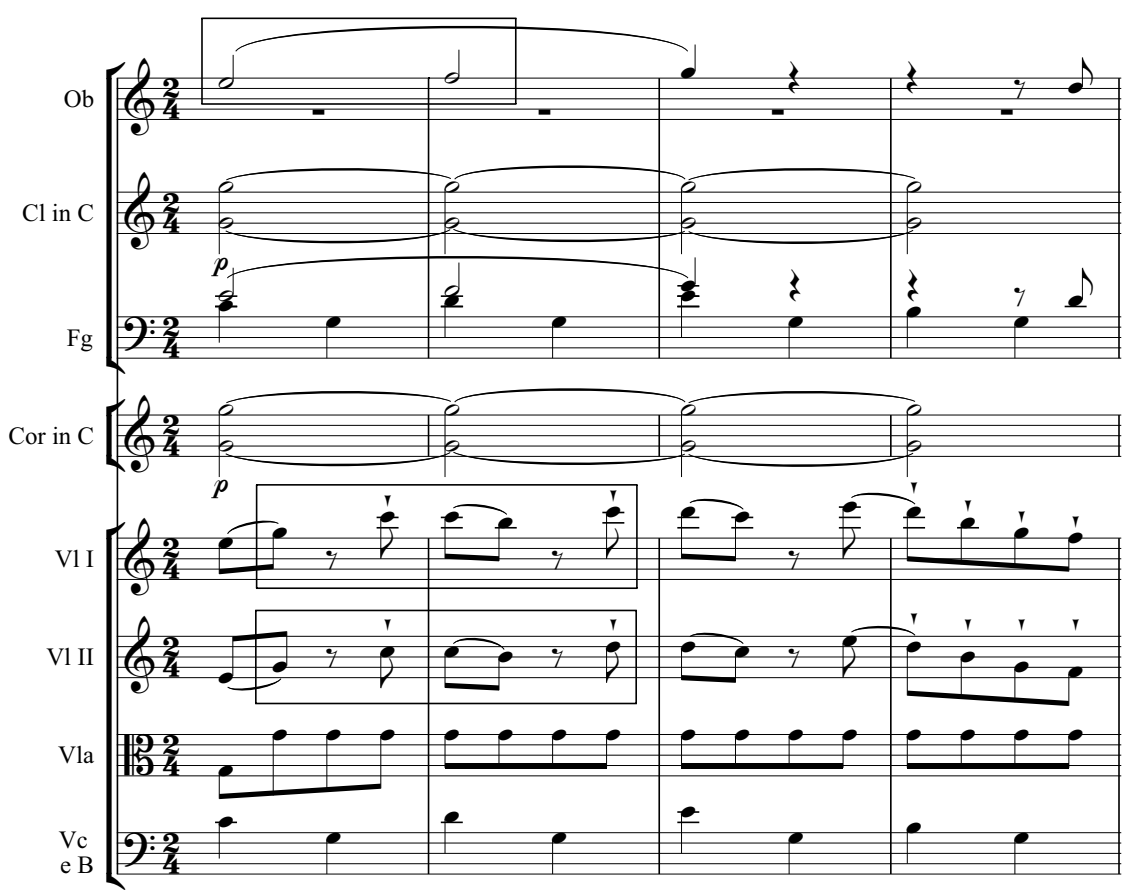

Example 4. Beethoven, Symphony No. 1, Last Movement, mm. 200-203

Since the salient question is the balance between the violins and the winds, Figure 1 presents the ranges, in decibels, of the relevant instrument, as measured in Sonic Visualizer; more precise figures, of course, could arguably be assigned to specific moments or even micro-seconds, but the concern here is with an overall balance, taken over the course of these passages.

\begin{tabular}{|l|l|l|l|l|l|l|l|l|}
\hline conductor & $\begin{array}{l}179-181 \\
1 \text { st bassoon }\end{array}$ & $\begin{array}{l}179-181 \\
\text { 2nd bassoon }\end{array}$ & $\begin{array}{l}179-181 \\
1 \text { st violins }\end{array}$ & $\begin{array}{l}179-181 \\
\text { 2nd violins }\end{array}$ & $\begin{array}{l}200-203 \\
\text { oboe }\end{array}$ & $\begin{array}{l}\text { 200-203 } \\
\text { 1st bassoon }\end{array}$ & $\begin{array}{l}\text { 200-203 } \\
\text { 1st violin }\end{array}$ & $\begin{array}{l}200-203 \\
\text { 2nd violin }\end{array}$ \\
\hline Hogwood & -33 to -20 & -34 to -25 & -41 to -27 & -36 to -22 & -36 to -21 & -27 to -20 & -36 to -23 & -31 to -22 \\
\hline Norrington & -33 to -22 & -32 to -22 & -32 to -28 & -31 to -24 & -29 to -19 & -28 to -21 & -32 to -26 & -25 to -21 \\
\hline
\end{tabular}

Figure 1. Decibel ranges of winds and violins in measures 179-181 and 200-203, in Hogwood's and Norrington's recordings $\mathrm{s}^{32}$

32 Decibels are always measured as ratios, from some reference measurement. Since all of the comparisons here will be between instruments measured against the same reference measurement, we need not concern ourselves with absolute values. Treating sound intensity this way also has the advantage of rendering irrelevant considerations such as the possibility of a higher overall recording sound intensity. The consistent negative values result from decibels' being expressed as a logarithm, base 10 . The larger negative numbers here, therefore, indicate less intensity and the smaller negative numbers greater intensity. 
Certain patterns start to emerge, already. While the bassoons in the earlier passage fall into quite similar ranges, Hogwood's first bassoon outweighs the second slightly, while Norrington's are more balanced; similarly, Hogwood's second violins considerably outweigh the first violins, while Norrington is, again, closer to being evenly balanced. ${ }^{33}$ In the later passage (with its more ripieno texture), Hogwood's oboe matches almost precisely the intensity of the first and second violins (not combined, of course), while the bassoon actually outdoes them. In Norrington's case, meanwhile, the oboe actually emerges more prominent than the bassoon, with both of them matching or outweighing the violin groups.

Figure 2 then compares each wind to each string section, one by one, in terms of signal strength, using the formula for logarithmic difference $X=10 \log \left(P_{2} / P_{1}\right) d B$, where $P_{1}$ and $P_{2}$ are the powers of the respective signals, and $X$ is the difference between their strengths. The mid-point of each range is taken as the variable. Here again, these being logarithms of ratios, the values are negative; and the larger the negative number, the greater the ratio of the first-named instrument's signal to that of the second-named instrument; and here, again, significant patterns emerge.

\begin{tabular}{|l|l|l|l|l|}
\hline conductor & $\begin{array}{l}179-1811^{\text {st }} \text { bassoon } \\
\text { difference to } 1^{\text {st }} \text { violins }\end{array}$ & $\begin{array}{l}179-1811^{\text {st }} \text { bassoon } \\
\text { difference to } 2 \text { nd violins }\end{array}$ & $\begin{array}{l}179-1812^{\text {nd }} \text { bassoon } \\
\text { difference to } 1^{\text {st }} \text { violins }\end{array}$ & $\begin{array}{l}179-1812^{\text {nd }} \text { bassoon } \\
\text { difference to } 2^{\text {nd }} \text { violins }\end{array}$ \\
\hline Hogwood & -1.082 & -0.392 & -0.617 & -0.742 \\
\hline Norrington & -0.378 & -0.080 & -0.458 & -0.797 \\
\hline
\end{tabular}

\begin{tabular}{|l|l|l|l|l|}
\hline conductor & $\begin{array}{l}200-203 \text { oboe } \\
\text { difference to } 1^{\text {st }} \text { violins }\end{array}$ & $\begin{array}{l}200-203 \text { oboe } \\
\text { difference to } 2^{\text {nd }} \text { violins }\end{array}$ & $\begin{array}{l}200-2031^{\text {st }} \text { bassoon } \\
\text { difference to } 1^{\text {st }} \text { violins }\end{array}$ & $\begin{array}{l}200-2031^{\text {st }} \text { bassoon } \\
\text { difference to } 2^{\text {nd }} \text { violins }\end{array}$ \\
\hline Hogwood & -0.150 & 0.360 & -0.988 & -0.522 \\
\hline Norrington & -0.822 & 0.185 & -0.732 & 0.274 \\
\hline
\end{tabular}

Figure 2. Comparative strengths of signals from instrument pairs in selected passages from Hogwood's and Norrington's recordings

In both recordings, all of the instrumental pairings favor the winds over the strings, with the exception of the oboe and the second violins in measures 200-203, which in both recordings favor the strings over the wind instrument. In that sense, then, the recordings do not reflect the publicly-touted favoring of wind in the orchestral balance (at least not in an absolute sense), but they remain similar in their treatment of that balance. That fact takes on particular significance, given that the latter is, in fact, a ripieno passage (which may also account, of course, for its one anomalous value). There is only one spot in which the recordings actually differ in their treatment of wind/string balance, namely in the first bassoon's ratio to the second violins in measures 200-203; there, the Hogwood recording has a fairly pronounced emphasis on the bassoon, while the Norrington recording somewhat more weakly favors the violins. So this is one place in which we

33 This latter observation is underlined by the fact that the first violins here play an octave above the seconds; therefore, the first violins' intensity (in both recordings, of course) will be somewhat reinforced by the first partial of the second violins. 
might say that individual difference outweighs shared aesthetic priorities. And while the recordings are remarkably similar in the absolute values of weighing instrumental groups over others, there are also discrepancies of degree: while the second bassoons in measures 179-181 predominates similarly in both recordings, for instance, the first bassoon there is much more prominent in Hogwood's (by a factor of roughly three or four).

More generally, then, both recordings, judging from these excerpts, seem to manifest some version of the aesthetic prescription (or was it a boast?) of HIP practitioners of the mid-1980s, of boosting the balance of wind choirs against the string sections of the orchestra and allowing wind parts to be heard clearly. But what evidence could one adduce that these particular aesthetic values and preferences are formed in some way endemic to urban cultural/economic activity? After all, HIP was not, even that time, a parochial musical movement, having strong presence in other cities like Amsterdam, Basel, Vienna, New York, and Boston; why could these two recordings not simply be reflecting a generalized preference, in the community of HIP performance, for favoring the balance of winds against strings?

In order to rule out that possibility, we might bring into consideration a third recording of the same work by another HIP specialist, the 1987 recording of the Smithsonian Chamber Orchestra, under the direction of violinist/conductor Jaap Schröder. Again, like most professional musicians and conductors, Schröder has been associated with a number of orchestras and ensembles (about which a bit more will be said presently). At the time of this recording, he was mainly associated with Washington, D.C., and the Smithsonian Institute, with whom he at that time not only directed the Chamber Orchestra, but also played first violin in the Smithson String Quartet. He also, at that time, was employed by Yale University's School of Music in New Haven, and that in itself suggests a more wide-ranging way to conceptualize urban places, at the scale of the region or sites of interrelated nodes, rather than as discrete cities; ${ }^{34}$ in particular, a U.S. East-Coast 'scene' of largely freelance HIP performers (such as Linda Quan, who plays first violin in Schröder's recording, as well as in numerous ensembles and orchestras in the New York and Boston areas), at the time of the recording, dominated much of the HIP musical performance, and continues to do so. ${ }^{35}$ Theorizing this somewhat more complex model of urban musical creativity will have to await a further essay; for the moment, one may think of the Smithsonian Chamber Orchestra as having grown as a node in a system of shifting and flexible professional affiliations variously centered, at that time, in Boston, New York, Philadelphia, and Washington, D. C.. (Of course, Schröder himself may be said to extend that network to New Haven, where other players like Laurence Dreyfus were located, though much of his professional playing, at that time, took place in nearby New York City.)

Figure 3 reproduces the data from Figure 1, adding in the measurements from Schröder's recording.

34 For example, Marcuse and van Kampen 2000.

35 While many of the players in Hogwood's and Norrington's orchestras were also freelancers, they more often worked within a single-city, rather than a regional, scale. 


\begin{tabular}{|l|l|l|l|l|l|l|l|l|}
\hline conductor & $\begin{array}{l}179-181 \\
1^{\text {st }} \text { bassoon }\end{array}$ & $\begin{array}{l}179-181 \\
2^{\text {nd }} \text { bassoon }\end{array}$ & $\begin{array}{l}179-181 \\
1^{\text {st }} \text { violins }\end{array}$ & $\begin{array}{l}179-181 \\
2^{\text {nd }} \text { violins }\end{array}$ & $\begin{array}{l}200-203 \\
\text { oboe }\end{array}$ & $\begin{array}{l}200-203 \\
1^{\text {st }} \text { bassoon }\end{array}$ & $\begin{array}{l}200-203 \\
1^{\text {st }} \text { violin }\end{array}$ & $\begin{array}{l}200-203 \\
2 \text { nd violin }\end{array}$ \\
\hline Hogwood & -33 to -20 & -34 to -25 & -41 to -27 & -36 to -22 & -36 to -21 & -27 to -20 & -36 to -23 & -31 to -22 \\
\hline Norrington & -33 to -22 & -32 to -22 & -32 to -28 & -31 to -24 & -29 to -19 & -28 to -21 & -32 to -26 & -25 to -21 \\
\hline Schröder & -31 to -24 & -34 to -25 & -44 to -31 & -46 to -35 & -26 to -21 & -25 to -19 & -36 to -21 & -25 to -19 \\
\hline
\end{tabular}

Figure 3. Decibel ranges of winds and violins in measures 179-181 and 200-203, in Hogwood's, Norrington's, and Schröder's recordings

Figure 4 then does analogously for Figure 2, adding the data from Schröder's recording.

\begin{tabular}{|l|l|l|l|l|}
\hline conductor & $\begin{array}{l}179-1811^{\text {st }} \text { bassoon } \\
\text { difference to } 1^{\text {st }} \text { violins }\end{array}$ & $\begin{array}{l}179-1811^{\text {st }} \text { bassoon } \\
\text { difference to } 2^{\text {nd }} \text { violins }\end{array}$ & $\begin{array}{l}179-1812^{\text {nd }} \text { bassoon } \\
\text { difference to } 1^{\text {st }} \text { violins }\end{array}$ & $\begin{array}{l}179-1812^{\text {nd }} \text { bassoon } \\
\text { difference to } 2^{\text {nd }} \text { violins }\end{array}$ \\
\hline Hogwood & -1.082 & -0.392 & -0.617 & -0.742 \\
\hline Norrington & -0.378 & -0.080 & -0.458 & -0.797 \\
\hline Schröder & -1.347 & -1.681 & -1.042 & -1.376 \\
\hline
\end{tabular}

\begin{tabular}{|l|l|l|l|l|}
\hline conductor & $\begin{array}{l}200-203 \text { oboe } \\
\text { difference to } 1^{\text {st }} \text { violins }\end{array}$ & $\begin{array}{l}200-203 \text { oboe } \\
\text { difference to } 2^{\text {nd }} \text { violins }\end{array}$ & $\begin{array}{l}200-2031^{\text {st }} \text { bassoon } \\
\text { difference to } 1^{\text {st }} \text { violins }\end{array}$ & $\begin{array}{l}200-2031^{\text {st }} \text { bassoon } \\
\text { difference to } 2^{\text {nd }} \text { violins }\end{array}$ \\
\hline Hogwood & -0.150 & 0.360 & -0.988 & -0.522 \\
\hline Norrington & -0.822 & 0.185 & -0.732 & 0.274 \\
\hline Schröder & -0.838 & 0.286 & -1.124 & 0.000 \\
\hline
\end{tabular}

Figure 4. Comparative strengths of signals from instrument pairs in selected passages from Hogwood's, Norrington's, and Schröder's recordings

Certain patterns emerge here, too, some familiar and some quite different from those that already emerged in the comparisons of Hogwood and Norrington. The pattern of negative and positive numbers follows very closely the pattern established in the earlier recordings (including the relative dominance of the second violins to the oboe in measures 200-204), with the one exception occurring in the area in which Hogwood and Norrington had diverged, namely the proportion of the first bassoon to the second violins in measures 202-203; there, Schröder splits the difference (though by no means exactly), so to speak, with a score of exactly zero. ${ }^{36}$ In that sense, one may at least consider the possibility that all three recordings display patterns that might be attributed, at least provisionally, to HIP performance of the mid-1980s. (Of course, establishing that would necessarily involve a base of comparisons for which there is no space in this essay.)

But there are also pronounced differences in the Schröder recording, not so much in the respective predominance of the voicings as in their proportions. In most of the proportions, the Schröder displays a far more pronounced predominance of winds over violin groups; for instance in the proportion of the first bassoon to the second violins in mm. 179-181, Schröder's recording dwarfs the values of the other two, corresponding

36 It is worth keeping in mind that, these calculations being logarithmic and a measure of proportions, a score of zero corresponds to an exact match in the midpoints of the decibel ranges of the two instrumental groups. 
to a hypothetical proportional loudness of four times that of Hogwood and more than twenty-one times that of Norrington (perceived loudness varying logarithmically with signal intensity). ${ }^{37}$ While not all of the differences are as dramatic as that, with the exception noted above and the general anomaly of the oboe/second-violin proportion in measures 200-203, Schröder consistently tips the balance toward the winds, generally in a quite striking proportion, compared to his London peers. ${ }^{38}$

The quantitative measurements suggest a truly qualitative difference in the Schröder recording's wind/violin balances; not all of the measurements reflect that, but enough do, and dramatically enough, to imply a qualitative difference. And that difference is indeed audible, in the measures here examined, and indeed, throughout the recording. Taken as a whole, the measurements performed on these three recordings together suggest that while the broadly and publicly shared values and practices of HIP performance all elicit a weighting of wind balances (an aesthetic value also, as seen earlier, reflected in the accompanying literature), there are strongly characterized differences of scale. That, in turn, suggests that internationally-shared values might themselves be subjected to local variations, variations shared in the kind of personal interactions discussed in the urban-geography literature. The relative similarity of Hogwood and Norrington, against Schröder, suggests some degree of shared aesthetic values and practices - precisely the kinds of things theorized by Storper, Scott, and Negus, the latter of whom discusses, in his ethnographic work, the blurring of lines between leisure and work, and the social inculcation of aesthetic values among employees of record companies. ${ }^{39}$ While Negus does not underline the urban context of his examples, they seem invariably to be urban, and of course, Storper and Scott are far more explicit about the city and its role in this kind of learning; and while Negus is describing the production and taste development of popular music, there is nothing about his description that limits it to any particular genre of music. With art music, aesthetic values are often taught more formally than in popular music (despite the rise of popular-music conservatories), but cultivation and development of those values continues throughout the careers of musicians, in more informal contexts. What the work of Storper, Scott, and others contributes to that equation is the specification of which aspects of cities, and their spatiality, help to form and support these processes. The values reflected in these recordings are not simply local variations but also evince habits of performance imparted in F2F circumstance - aspects of production critically supported by urban environments.

There are two issues that may arise, in the wake of what has been observed here. First, while it is true that all three conductors have had international careers, and certainly Hogwood and Norrington had long been based in the London musical world when their recordings were made, Schröder's own path had brought him into quite significant interaction with Hogwood himself, and his orchestra The Academy of Ancient Music; he recorded the complete Mozart symphonies as its concertmaster, with Hogwood con-

37 Norwich et al., 1998.

38 By contrast, the tempi of the three conductors are nearly identical, with Norrington's performance taking 5'30", Schröder's 5'31", and Hogwood's 5'32".

39 Negus 1992. 
ducting (1981-1983), and he recorded and performed other works with them in the early 1980s. Thus, his separation from London and its informally-cultivated music-aesthetic values is far from complete. That fact, however, in itself strongly argues that it is not formal training or (in this case) affiliation that necessarily shapes a performer's interpretations, but rather a more complex combination of those factors (and, certainly, others) with the performer's immersion in an formally- and informally-cultivated set of aesthetic values and knowledge. Schröder's interpretations were shaped, in part, by where he was, more than where he had been. In that sense, pedigree may often be overemphasized in our descriptions of musicians, as opposed to their immediate setting.

Second, a conductor can hardly be said to be the sole figure responsible for the properties of a recording. Musicologists recently have emphasized how a recording is hardly an empty vessel conveying a disinterested document of a performance, but rather is profoundly shaped by its medium and the circumstances of its production, both technical and social; ${ }^{40}$ and even short of these often quite sophisticated critiques, a recording of an orchestra is hardly one of an individual. Hogwood, for instance, cannot be held solely responsible, beyond all doubt, for the balance of the strings and winds in his recording, as the musicians themselves are playing (and cannot be controlled completely, even by more demanding conductors than Hogwood), and there is also the matter of the engineers and producers of the recording. These practical and theoretical factors, as strong as they are, in fact argue in favour of thinking of music recording in terms of urban geography; after all, the urban experience of the city of London, and its spaces of socialization and sites of learning and aesthetic innovation, is precisely the thing that unites every single actor involved in the production of both Hogwood's and Norrington's recordings. The urban agglomeration of industry personnel in London, and the formation of their taste, embrace all of the players in the recording beyond any recognized performer, the formation of taste being a matter of urban externalities; the engineers can be seen as part of the same city ecology, and the recording thus to convey that ecology's broader priorities. Thinking of a performance (or, in this case, a recording) as shaped by a geographic unit, rather than by the aesthetic priorities of a single controlling intelligence, may well, in fact, prove to be a richer and more fertile way to conceptualize music performance, as a whole; what we have seen from the Hogwood, Norrington, and Schröder examples, for instance, suggests a notion of aesthetic communities that shape the very sounds of musical performances, the priorities with which scores are turned into sound. That very point can, in itself, be taken to critique the very practice of this essay in naming the recordings after their conductors - a shorthand, to be sure, but perhaps in some cases, a misleading one.

Understanding the role that cities can play in forming performance practice (and not just in HIP, of course) offers not just explanatory value, but also possible heuristic value, to the music theorist engaged with the analysis of musical performance. By extension, theorists interested in artworks per se may conceptualize the learning processes and aesthetic values of composition in similar ways, mutatis mutandis. While music textbooks and even scholarly writing often refer to national schools of composition, some of the 
theory presented here may suggest that historians and theorists re-scale those concepts (in appropriate circumstances, of course) to the level of the city (or perhaps, as in the case of Schröder, the urban region, the latter case involving cities that are geographically reasonably proximate, with large numbers of networks between or among them).

It is also important to distinguish such urban formations of performance style from other determinants, such as those embedded in formal training. ${ }^{41}$ Of course, formal training can be crucial in passing on many performance traditions and long have done so, and many musicians present themselves in terms of their training and various traditions of pedagogy, often extending to a famous pedagogue and/or composer. ${ }^{42}$ While there is no doubt that indeed such traditions constitute a shaping force in musical performance, the urban determinants being described here do not fall into this category; indeed, if they did, then they would say nothing more interesting than that such training generally takes place in cities - which is true, by and large, but not particularly revealing. Instead, the research of Storper, Scott, and others researching urban creativity, as well as that of Negus, together suggest something more specific to the urban environment, namely the sharing of knowledge and preferences that develops in the numerous informal, face-to-face exchanges that often blur the line between work and leisure. Urban musicians will attend formal training sessions at times, to be sure, but in many cases more frequently, they will encounter colleagues, students, and mentors at concerts, bars, restaurants, outside concert halls, and in the street; it is these kinds of casual encounters, and the exchanges of ideas and opinions that they engender, for which cities provide the unique facilities and opportunities for teaching and learning ${ }^{43}$ that Scott sees as crucial to the success of urban creative industries. Of course, Scott, as an economic urban geographer, is concerned with the productive value and economic success of these industries, whereas we, as music theorists, are more concerned with the artistic and aesthetic outcomes of these numerous casual encounters and sharings of information and opinion. But the outcomes are comparable, as Scott, after all, is discussing creative economies, in which the end product is not tangible products, but rather information, design, and aesthetics. In point of fact, the artistic preferences and practices discussed in this essay are not exclusively the outcome of these informal encounters, but rather stem from their combination with the more formal practices more frequently seen as forming musicians's playing style (such as conservatory training, and so on); Scott, along with urban geographer Dominic Power, refer to this combination as "complex value-added networks;" ${ }^{\prime 4}$ they also observe that as "firms in cultural-products industries are subject to competitive and organizational pressures such that they frequently agglomerate together in dense specialized clusters or industrial districts, while their products circulate with increasing ease on global markets." ${ }^{\prime \prime 5}$ Other factors also influence this tendency toward agglomeration in

41 For example, those described in Rubinoff 2006, or more critically described in Kingsbury 1988 and Nettl 1995.

42 Rubinoff 2006, 203.

43 Scott 2000, 2-15.

44 Power 2004, 3.

45 Power 2004, 4. 
the classical-music industry (and indeed, other music industries), such as the tendency toward a high percentage of temporary and freelance work, and the concomitant need for many music workers to engage in various kinds of social networking, in order to maintain a sufficient supply of employment. ${ }^{46}$ This tendency toward physical agglomeration, which Scott and others have long associated with the music industry, ${ }^{47}$ provides a slightly different view of essentially the same phenomenon: for the informal networks and learning instances to occur, and indeed for work to occur in the first place, the players involved need physical proximity and the facilities for such encounters - precisely the kinds of physical proximity and facilities provided by cities. This is, indeed, the sense in which the kinds of learning that help to form music-performance style may properly be tagged as 'urban;' that term, of course, lies a great distance from the broader sense of 'urban' that our society generally applies to music. And to some scholars, it may thus seem perverse to think of 'classical' music as somehow an urban phenomenon; but in this very different (and incidentally, far more literal) sense of the word 'urban,' classical music performance styles are indeed very much urban phenomena. Understanding the city as a crucial determinant to the style of musical performance can help music theorists, especially those working in that growing field of analyzing musical performance, to understand in a fuller and more nuanced way what kinds of processes go into the music, as it is heard. Since it is about how music sounds, and the relationship between the score and its realization as music, studying such things is most emphatically the work of a music theorist. My own approaches (such as in Krims 2007) borrow promiscuously and unapologetically from musicology and ethnomusicology, as well, which is probably necessary, if one wants to present as full a picture as possible; but the work of music theorists, whether along the lines of what I have done here or along the lines of what some of the theorists that I have cited here have done, will be critical to understanding this much-understudied aspect of music.

\section{References}

Ashby, Arved. 2010. Absolute Music, Mechanical Reproduction. Berkeley: University of California Press.

Bowen, José A. 1999. "Finding the Music in Musicology: Performance History and Musical Works." In Rethinking Music. Edited by Nicholas Cook and Mark Everist. Oxford: Oxford University Press.

Butt, John. 2002. Playing With History: The Historical Approach to Music Performance. New York: Cambridge University Press.

Cook, Nicholas. 2003. "Stravinsky Conducts Stravinsky." In The Cambridge Companion to Stravinsky. Edited by Jonathan Cross. Cambridge: Cambridge University Press.

46 Scott and Power 2004, 6.

47 For example, Krims 2007. 
_. "Prompting Performance: Text, Script, and Analysis in Bryn Harrison's être temps." Music Theory Online 11/1 (accessed 12 February, 2010).

—. 2007. The Schenker Project: Culture, Race, and Music Theory in Fin-de-Siècle Vienna. Oxford: Oxford University Press.

Day, Timothy. 2000. A Century of Recorded Music: Listening to Music History. New Haven: Yale University Press.

Damschroder, David. 2008. Thinking About Harmony: Historical Perspectives on Analysis. Cambridge: Cambridge University Press.

Dineen, Murray. 2009. "The 'Cellist's Predicament, or, Imagination, Ethics, and Musical Performance." International Review of the Aesthetics and Sociology of Music 40/2: 283-297.

Dodson, Alan. 2008. "Performance, Grouping, and Schenkerian Alternative Readings in Some Passages in Beethoven's Lebewoh/ Sonata." Music Analysis 27/1: 107-134.

Fink, Robert. 2005. Repeating Ourselves: American Minimal Music as Cultural Practice. Berkeley: University of California Press.

Honisch, Stefan Sunandan. 2009. "'Re-Narrating Disability' Through Musical Performance." Music Theory Online 15/3-4 (accessed 12 February, 2010).

Johnson, Stephen. 1990. "Beethoven Symphony Cycles: Stephen Johnson Discusses the Available CD Sets of Beethoven Symphonies." Gramophone, October 1990: 50-57.

Katz, Mark. 2004. Capturing Sound: How Technology Has Changed Music. Berkeley: University of California Press.

Kehoe, John. 1985. "Harnoncourt and Teldec - 21 Years On." Gramophone, March 1985: 1045.

Kingsbury, Henry. 1988. Music, Talent, \& Performance: A Conservatory Cultural System. Philadelphia: Temple University Press.

Krims, Adam. 2007. Music and Urban Geography. New York: Routledge.

Leech-Wilkinson, Daniel. 2009. The Changing Sound of Music: Approaches to the Study of Recorded Musical Performances. London: CHARM.

MacDonald, David A. 2009. "Poetics and the Performance of Violence in Israel/Palestine." Ethnomusicology 53/1: 58-85.

Marcuse, Peter and Ronald van Kampen. 2000. Globalizing Cities: A New Spatial Order? Hoboken: Riley-Blackwell.

McClary, Susan. 2009. "Adorno Plays the WTC: On Political Theory and Performance." Indiana Theory Review 27/2: 97-112.

Negus, Keith. 1992. Producing Pop: Culture and Conflict in the Popular Music Industry. London: Hodder Arnold.

Nettl, Bruno. 1995. Heartland Excursions: Ethnomusicological Reflections on Schools of Music. Urbana-Champaign: University of Illinois Press.

Norwich, Kenneth, Willy Wong, and Elad Sagi. 1998. "Range as a Factor Determining the Information of Loudness Judgments: Overcoming Small Sample Bias." Canadian Journal of Experimental Psychology 52/2: 63-71. 
Plourde, Lorraine. 2008. "Disciplined Listening in Tokyo: Onkyo and Non-Intentional Sounds." Ethnomusicology 52/2: 270-295.

Rubinoff, Kailan. 2006. The Early Music Movement in the Netherlands: History, Pedagogy, and Ethnography. Ph. D. Diss., University of Alberta.

Scott, Allen J. 2000. The Cultural Economy of Cities. London: Sage.

Shelemay, Kay Kaufman. 2001. "Toward an Ethnomusicology of the Early Music Movement: Thoughts on Bridging Disciplines and Musical Worlds." Ethnomusicology 45/1: $1-29$.

Sterne, Jonathan. 2003. The Audible Past: Cultural Origins of Sound Reproduction. Durham: Duke University Press.

Storper, Michael and Anthony J. Venables. 2004. "Buzz: Face-to-Face Contact and the Urban Economy." Journal of Economic Geography 4: 351-370.

Taruskin, Richard. 1995. Text and Act: Essays on Music and Performance. Oxford: Oxford University Press.

\section{Discography}

Hogwood, Christopher. 1986. Beethoven: Symphonies 1 and 2, with the Academy of Ancient Music. L'Oiseau Lyre 414 338-2.

Norrington, Roger. 1988. Beethoven: Symphony no. 1 in C major, op. 21; Symphony no. 6 in F major, op. 68: "Pastorale," with the London Classical Players. Decca 7497462.

Schröder, Jaap. 1989. Ludwig van Beethoven: Symphony No. 1 C-Dur, Op. 21, Symphony No. 3, Es-Dur, Op. 55, "Eroica," with the Smithsonian Chamber Orchestra. Deutsche Harmonia Mundi 77030-2-RC. 